\title{
Rainfall Kinetic Energy in Denmark: Relationship with Drop Size, Wind Speed, and Rain Rate $\mathscr{D}$
}

\author{
ANNA-MARIA TILG \\ Department of Wind Energy, Technical University of Denmark, Roskilde, Denmark \\ FLEMMING VEJEN \\ Danish Meteorological Institute, Copenhagen, Denmark \\ Charlotte Bay Hasager AND Morten Nielsen \\ Department of Wind Energy, Technical University of Denmark, Roskilde, Denmark
}

(Manuscript received 28 October 2019, in final form 3 June 2020)

\begin{abstract}
Rainfall kinetic energy is an important parameter to estimate erosion potential in connection to soil erosion or in the recent years to the erosion of the leading edges of wind turbine blades. Little is known about the seasonal drop size distribution and fall velocity dependence of rainfall kinetic energy as well as its relationship with wind speed. Therefore, 6 years of Thies Laser Precipitation Monitor disdrometer and wind measurements from Voulund, a field site in western Denmark, were analyzed. It was found that the rainfall kinetic energy was highest in summer due to higher drop concentrations and in autumn due to more time with rain. The rainfall kinetic energy peaked for drop diameters between 0.875 and $2.25 \mathrm{~mm}$ independent of the season. Rainfall kinetic energy decreased significantly with increasing wind speed, if considering the vertical fall speed of the drops for the calculation of the rainfall kinetic energy. However, it should be noted that the measurement uncertainty increases with increasing wind speed. As disdrometer observations are rarer than rain rate observations, the performance of empirical equations describing the relationship between rainfall kinetic energy rate and rain rate was investigated. It was found that an equation trained with an alternative method fulfilled the statistical requirements for linear regression and had a similar error compared to equations in the literature. Based on the analyses, it can be concluded that the erosion potential due to rainfall kinetic energy is highest between June and November at low wind speeds and high rain rates.
\end{abstract}

\section{Introduction}

Rainfall kinetic energy (KE) is a dominant factor for erosion processes, because KE provides energy for the detachment of particles from the surface. A prominent example is soil erosion where rainfall beside other environmental influences causes soil degradation (Wischmeier and Smith 1958; Naipal et al. 2015; Panagos et al. 2015). Another example is erosion of the leading edges of wind turbines blades. This kind of blade degradation depends

Supplemental information related to this paper is available at the Journals Online website: https://doi.org/10.1175/JHM-D-190251.s1.

Corresponding author: Anna-Maria Tilg, anmt@dtu.dk on the raindrop size (Keegan et al. 2013; Mishnaevsky 2019) and the rotation of the blades, which adds significant additional velocity for the drop impact (Amirzadeh et al. 2017). Bech et al. (2018) propose to reduce the tip speed of the wind turbine blades during severe rain events to reduce leading edge erosion (LEE). Detailed quantification of the rain climate, in particular of KE and drop size distribution (DSD) as well as its interaction with wind speed in different environments is needed for improved understanding of LEE.

KE itself is a function of DSD and fall velocity of the drops. The only direct way to determine $\mathrm{KE}$ is by counting the number of drops and observing their sizes and fall velocities. Kathiravelu et al. (2016) give an overview of different methods to measure DSD and fall velocity of the drops where nowadays disdrometers are 
the most common instrument for DSD observations. However, one has to keep in mind that only drops with a diameter up to $1 \mathrm{~mm}$ have a spherical shape. Larger drops are flattened and therefore more like an ellipsoid. Gravity, buoyancy, and drag force govern the fall velocity of a drop in still air where the diameter and the shape of the drop determine the value (Jones et al. 2010). Terminal fall velocity is achieved when the buoyancy and the drag force balance gravity. DSD varies between different locations (e.g., Dolan et al. 2018), within rain events (e.g., D'Adderio et al. 2018) and between seasons (e.g., Wen et al. 2019). The causes for these spatiotemporal variations are mainly precipitation formation processes (warm versus cold clouds) and coalescence or breakup of drops due to collision. These processes also determine observed differences between convective and stratiform events (e.g., Suh et al. 2016) and between maritime and coastal locations (e.g., Das and Chatterjee 2018), where for the latter the aerosol concentration plays an important role. Bringi et al. (2003) compare DSD measured at different locations around the globe and find for convective rain a maritime-like cluster with a mass-weighted mean diameter $D_{m}$ between 1.50 and $1.75 \mathrm{~mm}$ and a continental-like cluster with $D_{m}$ between 2.00 and $2.75 \mathrm{~mm}$. In contrast, for stratiform rain they find no clear difference between maritime and continental locations. The variations of DSD imply that KE also changes with space and time. One of the few examples illustrating the seasonal variation of KE in Europe is published by Davison et al. (2005). They report higher KE values in late summer and autumn in England and Wales using an empirical equation between daily rainfall amount and KE. An important but often neglected parameter influencing the drop fall velocity and DSD is wind speed. MonteroMartínez and García-García (2016) and Thurai et al. (2019) report that in situations with high wind speeds the distribution of fall velocity values is broader and drops tend to have a lower fall velocity compared to situations with calm wind conditions. Thurai et al. (2019) mention the asymmetric shapes of drops within these situations as a possible cause. Furthermore, Testik and Pei (2017) show an increase of small drops and decrease of large drops with increasing wind speed due to increased breakup of drops with increasing wind speed. Pedersen and Hasholt (1995) find an increase of KE with increasing wind speed based on rain gauge data and calculations of KE with an exponential model. However, the direct impact of wind speed on KE due to variations of fall velocity and DSD is not well described in literature.

Disdrometers are usually not part of operational meteorological measurement networks. Therefore, several parameterizations for DSD and fall velocity exist in literature. Prominent examples for DSD distributions are the gamma distribution (Ulbrich and Atlas 1998), where the exponential distribution is a special case, and the lognormal distribution (Feingold and Levin 1986). Testud et al. (2001) propose doing a normalization of the raindrop spectra for improving the comparability of the DSD. The suggested parameters volume-weighted mean diameter $D_{m}$ and generalized intercept parameter $N_{W}$ describe the DSD and have the advantage that no specific distribution needs to be assumed. An overview of equations for calculation of the terminal fall velocity is given by Jones et al. (2010). Fox (2004) expresses rainfall KE and rain rate (RR) with the gamma distribution and the terminal drop velocity described by Ulbrich (1983) but finds no clear relationship between KE and RR.

The attempt of Fox (2004) is not surprising as the availability of RR is higher because of the worldwide measurement network of rain gauges and weather radars. This situation favors the use of empirical relationships using RR as input to estimate KE. There are several publications (e.g., Salles et al. 2002; van Dijk et al. 2002; Petan et al. 2010; Angulo-Martínez et al. 2016; Petrů and Kalibová 2018) that list relationships between RR and KE for different areas of the world, where KE is normalized either by time (h) or rain amount $(\mathrm{mm})$. While for countries in the low and midlatitudes several equations are published, less is known about KE-RR relationships in higher latitudes. This gap may be due to the small influence of rain on soil erosion in, e.g., northern European countries (Veihe et al. 2003). Apart from that, most empirical equations follow a power, logarithmic or exponential form but often it is not clear why the authors defined that kind of relationship and if assumptions using this type of equation are fulfilled (e.g., residual distribution). Furthermore, the time aggregation of RR plays an important role in the KE-RR relationship. Angulo-Martínez et al. (2016) demonstrate that KE is underestimated if another time aggregation of $\mathrm{RR}$ is used as compared to the input time scale used for the calibration of the KE-RR relationship.

The aim of this study is to determine conditions with a high potential for high KE. Therefore, we analyze the annual and seasonal variation of cumulative and averaged 10-min KE values and the wind speed dependence of KE. These variations are compared with the variations from DSD and fall velocity. Furthermore, we propose a model to describe the relationship between $\mathrm{KE}$ rate and RR and fulfilling assumptions related to linear regression fitting. These investigations are based 
TABLE 1. Instrumentation at field site Voulund, Denmark.

\begin{tabular}{|c|c|c|c|}
\hline Sensor & Manufacturer & $\begin{array}{l}\text { Measurement/orifice } \\
\text { height }(\mathrm{m})\end{array}$ & Note \\
\hline Laser Precipitation Monitor (LPM) & Thies Clima & 1.5 & \\
\hline Pluvio $^{2}$ & OTT & 0 & WMO reference rain gauge at ground level \\
\hline Pluvio $^{2}$ & OTT & 3 & $\begin{array}{l}\text { WMO reference rain gauge shielded with a } \\
\text { Tretyakov windshield and surrounded with a } \\
\text { Valdai double fence from November to March }\end{array}$ \\
\hline Pluvio $^{2}$ & OTT & 1.5 & WMO reference rain gauge unshielded \\
\hline Pluvio $^{2}$ & OTT & 1.5 & $\begin{array}{l}\text { WMO reference rain gauge shielded with a } \\
\text { Tretyakov windshield }\end{array}$ \\
\hline Pluvio $^{2}$ & OTT & 1.5 & $\begin{array}{l}\text { WMO reference rain gauge unshielded and operated } \\
\text { with solar panel }\end{array}$ \\
\hline RIM7499 & RIMCO & 1.5 & \\
\hline HMP45C & Campbell Scientific & 2 & \\
\hline Wind speed sensor 2740 & Aanderaa & 1.5 & \\
\hline
\end{tabular}

on 6 years of disdrometer measurements at a field site in Denmark.

\section{Data and methods}

\section{a. Disdrometer data and their quality control}

Precipitation and other meteorological parameters were measured at Voulund $\left(56.0372426^{\circ} \mathrm{N}, 9.159357^{\circ} \mathrm{E}\right.$, $67 \mathrm{~m}$ ), a flat open area with a size of around $2000 \mathrm{~m}^{2}$ and no nearby obstacles, in western Denmark in connection to the Danish hydrological observatory (HOBE) project (Jensen and Illangasekare 2011). The focus of the HOBE project was the investigation of the influence of natural and anthropogenic changes on hydrological processes within the Skjern River catchment. The Danish Meteorological Institute (DMI) provided access to precipitation, wind, and temperature measurements from February 2012 to December 2017 (6 years). Table 1 provides a detailed overview of the instrumentation. The focus of our analyses is on the Thies Laser Precipitation Monitor (LPM) disdrometer data.

The LPM disdrometer is an optical disdrometer manufactured by the company Adolf Thies $\mathrm{GmbH}$ and Co. KG in Germany. The precipitation particles attenuate the laser sheet between the transmitter and receiver when they fall through it. The risk of two drops concurrent in the laser sheet is negligible (Pickering et al. 2019). The laser operates at a wavelength of $785 \mathrm{~nm}$ and is $228 \mathrm{~mm}$ long, $20 \mathrm{~mm}$ wide, and $0.75 \mathrm{~mm}$ high. An internal algorithm calculates the equivolumetric diameter and vertical fall velocity of every precipitation particle and collates them into different classes considering 22 different size classes (from $\geq 0.125$ to $\geq 8 \mathrm{~mm}$ ) and 20 different velocity classes (from $\geq 0$ to $\geq 10 \mathrm{~m} \mathrm{~s}^{-1}$ ) both with varying class width. The time resolution of the original data was $1 \mathrm{~min}$. The other parameters provided by DMI had a time resolution of $10 \mathrm{~min}$ and therefore the
LPM data were aggregated in 10-min statistics for compatibility with the remaining available data.

Upton and Brawn (2008), Frasson et al. (2011), and Angulo-Martínez et al. (2018) investigate in detail the LPM disdrometer and its characteristics compared to other precipitation sensors. The mentioned publications show a discrepancy between measurements of the LPM disdrometer and the other sensors. These differences can be explained for example by signal processing, splashing from the housing of the sensor or aerodynamic effects of the sensor on the precipitation field. As the precipitation is measured within a limited sampling area of the disdrometer, the measured DSD and consequent integral rainfall parameters include some uncertainty (Jaffrain and Berne 2011).

Friedrich et al. (2013) emphasize the importance of quality control of disdrometer data to remove background noise and unrealistic measurements caused for example by insects. Furthermore, for the present investigation all precipitation types except rain were removed although hail has a huge impact on the development of LEE of wind turbine blades (Macdonald et al. 2016; Letson et al. 2020). The criteria for the applied quality control use LPM data itself but also rain gauge and temperature measurements from the field site and radar data provided by DMI. Radar data for $3 \times 3$ pixels each with a size of $2 \times 2 \mathrm{~km}^{2}$ were available with a center pixel at the site of interest and eight neighbor pixels. While the distance between the LPM and the rain gauges was maximum $20 \mathrm{~m}$, the distance between LPM and radar was around $53.8 \mathrm{~km}$. The center of the radar beam is around $716 \mathrm{~m}$ above the field site in Voulund assuming standard atmosphere and an elevation angle of $0.5^{\circ}$. LPM data were removed based on the criteria listed in Table 2 .

In some cases, e.g., criterion 9 in Table 2, quality control by simple boundaries is not satisfying (Larsen 
TABLE 2. Criteria used for quality control of the LPM disdrometer data.

\begin{tabular}{|c|c|c|}
\hline Criterion & Description & Reference \\
\hline 1 & Status of LPM indicates error & \\
\hline 2 & Surface synoptic observation (SYNOP) code (from table 4677) indicates hail & Ghada et al. (2018) \\
\hline 3 & SYNOP code indicates snow & Ghada et al. (2018) \\
\hline 4 & SYNOP code indicates freezing precipitation & Ghada et al. (2018) \\
\hline 5 & 1 -min intensity $<0.1 \mathrm{~mm} \mathrm{~h}^{-1}$ & Tokay and Bashor (2010) \\
\hline 6 & Cumulative sum of drops $<10$ & Tokay and Bashor (2010) \\
\hline 7 & Data in less than five size-velocity combinations & Inspired by Ghada et al. (2018) \\
\hline 8 & Drops with a diameter $>8 \mathrm{~mm}$ & Friedrich et al. (2013) \\
\hline 9 & $\begin{array}{l}\text { Drops with a diameter }>2 \mathrm{~mm} \text { and with a fall velocity outside } \pm 60 \% \text { of the terminal } \\
\text { velocity based on the equation of Atlas et al. (1973) }\end{array}$ & Inspired by Friedrich et al. (2013) \\
\hline 10 & $\begin{array}{l}\text { Rain gauges registers no precipitation and radar measures no reflectivity indicating } \\
\text { precipitation }\end{array}$ & \\
\hline 11 & $\begin{array}{l}\text { All rain gauges register no precipitation and at least } 7 \text { radar pixels around the field site do } \\
\text { not indicate precipitation }\end{array}$ & \\
\hline 12 & Radar data are not available and rain gauges detect no precipitation & \\
\hline 13 & Precipitation at temperatures below the freezing point & \\
\hline
\end{tabular}

and Schönhuber 2018). Small drops with a terminal velocity outside a specific range of the terminal velocity can be drops splashed from the housing as mentioned for example by Angulo-Martínez et al. (2018). Montero-Martínez et al. (2009) and Montero-Martínez and García-García (2016) investigate the physical background of such superterminal and subterminal velocities of smaller drops. In contrast to Angulo-Martínez et al. (2018), they conclude that breakup and coalescence processes of drops shortly before falling through the laser sheet can cause such differences from the terminal velocity.

Table 3 gives an overview of missing 1-min measurements and removed 1-min measurements and drops for each year. The LPM was not running in January and end of December 2012 as well as end October 2014 to midJanuary 2015 . These circumstances caused the high fractions of missing values in 2012, 2014, and 2015. Con5 (1-min intensity $<0.1 \mathrm{~mm} \mathrm{~h}^{-1}$ ) caused the highest percentage of removed intervals and particles. Con6 (Cumulative sum of drops $<10$ ) affected in comparison to Con5 more intervals but less the number of removed particles. A high percentage of particles were removed by Con3 (SYNOP code indicates snow), while the percentage of removed intervals due to this criterion was much lower.

Wind and precipitation data were only available with 10-min temporal resolution. Wind speed values are mean values over $10 \mathrm{~min}$. Wind speed and rain gauge measurements were already quality controlled by DMI.

The yearly rain amounts of all precipitation sensors at the field site were compared, neglecting other precipitation types than rain (see figure in the online supplemental material). While the LPM measured the highest yearly amounts, rain gauge RIM7499 registered 20\% and less rain. One cause might be that RIM7499 is a tipping bucket with a resolution of $0.2 \mathrm{~mm}$. Therefore, rain events with a low intensity had not been measured by RIM7499. Furthermore, it is known from different intercomparison experiments (e.g., Sevruk et al. 2009; Liu et al. 2013) that rain gauges even installed closely together measure different amounts or rain rates. These differences are caused for example by turbulence due to wind and evaporation influences as well as by different measurement principles.

\section{b. Calculation of integral rainfall parameters}

Integral rainfall parameters were calculated using the quality controlled disdrometer data with a temporal resolution of $10 \mathrm{~min}$. The equivolumetric diameter and the fall velocity measured by the LPM were used as input for all equations, where the equivolumetric diameter describes the diameter of a spherical drop that has the same volume as a flattened raindrop. For all calculations the central values of the diameter (summation index $i$ ) and fall velocity (summation index $j$ ) classes were used.

Rain rate $\left(\mathrm{RR} ; \mathrm{mm} \mathrm{h}^{-1}\right)$ is based on the equation from Frasson et al. (2011):

$$
\mathrm{RR}=\frac{1}{\frac{t}{60}} \frac{1}{A} \frac{\pi}{6} \sum_{i} n_{i} \times D_{i}^{3},
$$

where $D_{i}$ is in decimeters $(\mathrm{dm})$.

Rainfall kinetic energy per area $\left(\mathrm{KE} ; \mathrm{J} \mathrm{m}^{-2}\right)$ is based on Petrů and Kalibová (2018):

$$
\mathrm{KE}=\frac{1}{A} \frac{\rho \times \pi}{12} \sum_{i} \sum_{j} n_{i j} \times D_{i}^{3} \times v_{j}^{2},
$$

where $D_{i}$ is in millimeters (mm).

Rainfall kinetic energy rate $\left(\mathrm{KER} ; \mathrm{J} \mathrm{m}^{-2} \mathrm{~h}^{-1}\right.$ ) is calculated with the following equation: 
TABLE 3. Overview about missing and removed 1-min intervals and removed drops of the Thies LPM data collected in Voulund, Denmark.

\begin{tabular}{lcccccc}
\hline \multicolumn{1}{c}{ Year } & 2012 & 2013 & 2014 & 2015 & 2016 & 2017 \\
\hline Intervals (min) & 527040 & 525600 & 525600 & 525600 & 527040 & 525600 \\
Measured drops & 35977351 & 37261771 & 31255343 & 51559448 & 37268392 & 55170114 \\
Missing intervals (\%) & 17.69 & 5.25 & 23.61 & 8.64 & 5.41 & 5.16 \\
Con1 intervals/drops (\%) & $0.07 / 0.17$ & $0.10 / 0.07$ & $0.06 / 0.13$ & $0.02 / 0.45$ & $0.06 / 0.07$ & $0.03 / 0.09$ \\
Con2 intervals/drops (\%) & $0.07 / 1.33$ & $0.04 / 1.43$ & $0.04 / 1.43$ & $0.05 / 0.86$ & $0.04 / 0.70$ & $0.09 / 1.65$ \\
Con3 intervals/drops (\%) & $1.09 / 11.84$ & $3.34 / 18.13$ & $0.94 / 13.94$ & $1.15 / 7.23$ & $1.41 / 10.66$ & $1.46 / 6.58$ \\
Con4 intervals/drops (\%) & $0.00 / 0.00$ & $0.00 / 0.00$ & $0.00 / 0.00$ & $0.00 / 0.00$ & $0.00 / 0.00$ & $0.00 / 0.00$ \\
Con5 intervals/drops (\%) & $5.59 / 11.54$ & $4.95 / 11.09$ & $4.37 / 11.02$ & $6.99 / 12.40$ & $6.67 / 13.84$ & $7.03 / 12.34$ \\
Con6 intervals/drops (\%) & $6.37 / 0.25$ & $8.64 / 0.33$ & $10.26 / 0.50$ & $7.63 / 0.21$ & $7.41 / 0.28$ & $11.94 / 0.30$ \\
Con7 intervals/drops (\%) & $0.01 / 0.00$ & $0.02 / 0.00$ & $0.07 / 0.01$ & $0.01 / 0.00$ & $0.01 / 0.00$ & $0.02 / 0.00$ \\
Con8 intervals/drops (\%) & $0.07 / 0.01$ & $0.07 / 0.01$ & $0.06 / 0.01$ & $0.01 / 0.00$ & $0.06 / 0.01$ & $0.13 / 0.02$ \\
Con9 intervals/drops (\%) & $0.36 / 0.02$ & $0.36 / 0.01$ & $0.23 / 0.01$ & $0.45 / 0.01$ & $0.33 / 0.01$ & $0.45 / 0.02$ \\
Con10 intervals/drops (\%) & $2.36 / 0.70$ & $2.56 / 0.51$ & $1.88 / 0.59$ & $2.36 / 0.78$ & $2.74 / 0.98$ & $4.03 / 0.84$ \\
Con11 intervals/drops (\%) & $1.32 / 0.99$ & $1.26 / 0.51$ & $1.21 / 0.33$ & $1.17 / 0.31$ & $0.96 / 0.44$ & $1.18 / 0.59$ \\
Con12 intervals/drops (\%) & $0.00 / 0.00$ & $0.08 / 0.13$ & $0.00 / 0.00$ & $0.16 / 0.02$ & $0.07 / 0.02$ & $0.10 / 0.08$ \\
Con13 intervals/drops (\%) & $0.14 / 0.32$ & $1.05 / 0.15$ & $2.43 / 0.78$ & $0.04 / 0.02$ & $0.17 / 0.53$ & $0.22 / 0.22$ \\
\hline
\end{tabular}

$$
\mathrm{KER}=\frac{1}{\frac{t}{60}} \times \mathrm{KE} .
$$

Rainfall kinetic energy per area per diameter $\left[\operatorname{KE}\left(D_{i}\right)\right.$; $\mathrm{J} \mathrm{m}^{-2} \mathrm{~mm}^{-1}$ ] is calculated using this equation:

$$
\mathrm{KE}\left(D_{i}\right)=\frac{1}{A} \frac{\rho \times \pi}{12} \sum_{j} \frac{n_{i j} \times D_{i}^{3} \times v_{j}^{2}}{\Delta D_{i}}
$$

Following the equation in Chen et al. (2016), the number of drops per unit volume of air and per diameter interval $\left[N\left(D_{i}\right) ; \mathrm{m}^{-3} \mathrm{~mm}^{-1}\right]$ is calculated as

$$
N\left(D_{i}\right)=\sum_{j} \frac{n_{i j}}{A \times \Delta t \times v_{j} \times \Delta D_{i}} .
$$

Mean volume weighted diameter $\left(D_{m} ; \mathrm{mm}\right)$ is calculated based on Bringi et al. (2003):

$$
D_{m}=\frac{\sum_{i} N\left(D_{i}\right) \times D_{i}^{4} \times \Delta D_{i}}{\sum_{i} N\left(D_{i}\right) \times D_{i}^{3} \times \Delta D_{i}} .
$$

Liquid water content ( $\mathrm{LWC} ; \mathrm{g} \mathrm{m}^{-3}$ ) is calculated based on Hagen and Yuter (2003):

$$
\mathrm{LWC}=\rho \times \frac{\pi}{6} \times \sum_{i} D_{i}^{3} \times \Delta D_{i} \times N\left(D_{i}\right)
$$

with $\rho$ in grams per cubic millimeter $\left(\mathrm{g} \mathrm{mm}^{-3}\right)$.

The generalized intercept parameter $\left(N_{w} ; \mathrm{mm}^{-1} \mathrm{~m}^{-3}\right)$ is calculated based on Bringi et al. (2003):

$$
N_{w}=\frac{4^{4}}{\pi \times \rho} \times \frac{\mathrm{LWC}}{D_{m}^{4}} .
$$

The above equations use the following parameters with given units (if not indicated differently): $\rho$ is the density of water $\left(\mathrm{kg} \mathrm{m}^{-3}\right) ; t$ is the time aggregation interval (min); $\Delta t$ is the time interval of the observation (s); $A$ is the measuring area $\left(\mathrm{m}^{2}\right) ; n_{i}$ is the number of drops within the diameter class $i$ per time aggregation interval (considers all fall velocity classes); $D_{i}$ is the mean drop diameter in diameter class $i(\mathrm{~mm}) ; \Delta D_{i}$ is the width of size class $i(\mathrm{~mm}) ; v_{j}$ is the mean drop fall velocity in velocity class $j\left(\mathrm{~m} \mathrm{~s}^{-1}\right)$; and $n_{i j}$ is the number of drops within the size class $i$ and velocity class $j$.

The calculation of the mean fall velocity $V_{m}\left(\mathrm{~m} \mathrm{~s}^{-1}\right)$ is not a standard integral rainfall parameter and is therefore not found frequently in literature. The following used equations were refined based on a flowchart in Kim and Song (2018):

$$
\begin{gathered}
N\left(v_{j}\right)=\sum_{i} \frac{n_{i j}}{A \times \Delta t \times v_{j} \times \Delta v_{j}}, \\
V_{m}=\frac{\sum_{j} N\left(v_{j}\right) \times v_{j}}{\sum_{j} N\left(v_{j}\right)},
\end{gathered}
$$

with $N\left(v_{j}\right)$ being the velocity distribution in velocity class $j\left(\mathrm{~m}^{-3} \mathrm{~m}^{-1} \mathrm{~s}\right)$ and $\Delta v_{j}$ the width of the velocity class $\left(\mathrm{m} \mathrm{s}^{-1}\right)$.

\section{Results}

All results are based on quality controlled LPM disdrometer data and wind data with a 10-min resolution from 6-yr measurements at the field site Voulund in Denmark. 

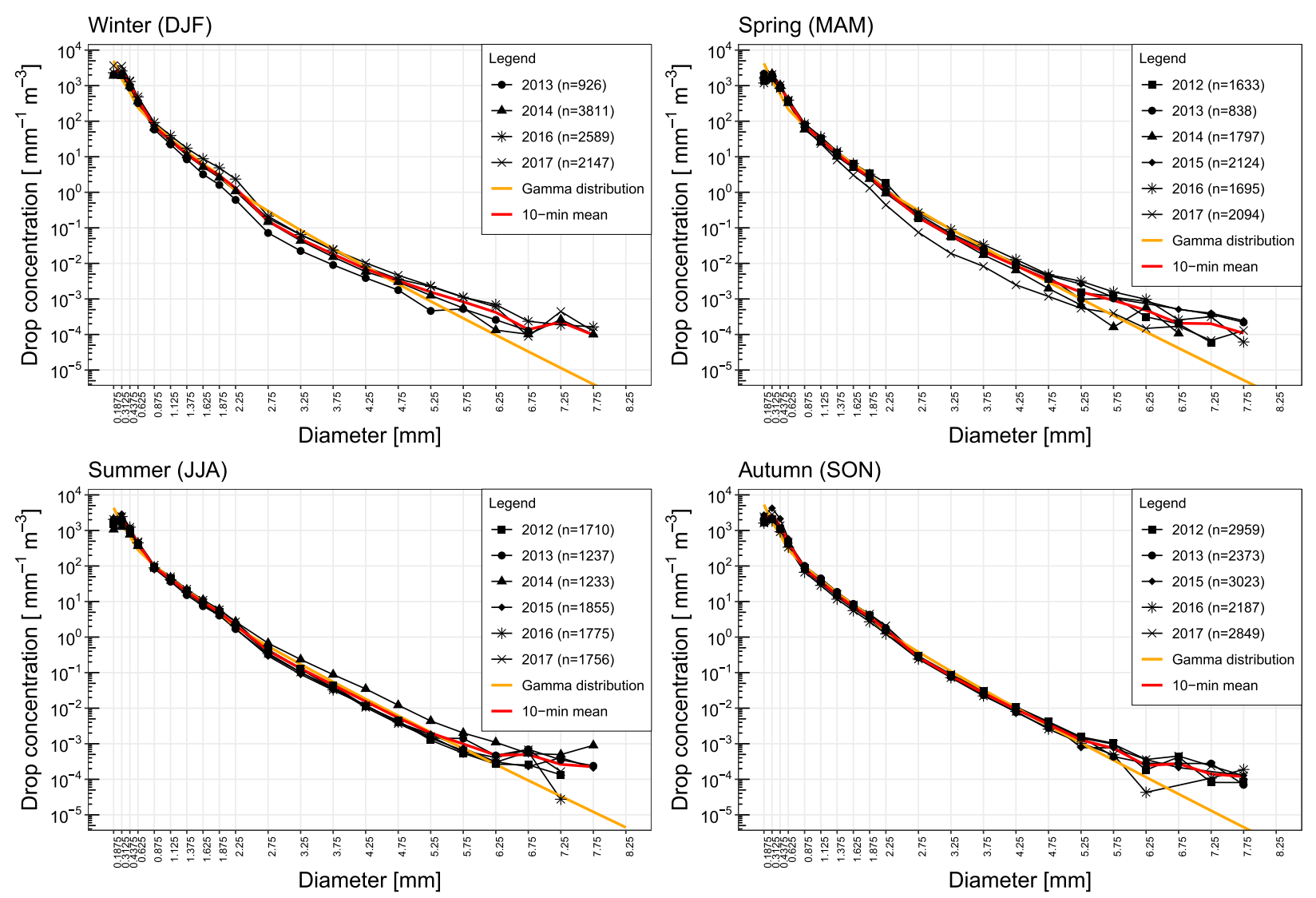

FIG. 1. Mean 10-min drop concentration per millimeter diameter and cubic meter of air $[N(D)]$ for different seasons and years. The orange line describes the gamma distribution fitted according to Ulbrich and Atlas (1998). The number of analyzed 10-min intervals is given in parentheses for each year separately.

\section{a. Annual and seasonal variation of drop size distribution, fall velocity, and rainfall kinetic energy}

To analyze the annual and seasonal variation of the parameters $N(D)$, fall velocity, and $\operatorname{KE}(D)$, the LPM data were divided into four seasons: winter (DJF), spring (MAM), summer (JJA), and autumn (SON). For each season and year the mean $[N(D), \operatorname{KE}(D)]$ and median (fall velocity) 10-min value, respectively, were calculated when the percentage of missing values in each month of the season was less than $25 \%$. Furthermore, a seasonal average was calculated using the data of all years (except the ones with a high fraction of missing values) and was compared with empirical fits.

Figure 1 compares the seasonal 10-min mean $N(D)$ with the yearly seasonal 10-min mean $N(D)$ and the fitted gamma distribution. For the fitting procedure of the gamma distribution the seasonal mean $N(D)$ was used as input as described in Ulbrich and Atlas (1998). Within the different seasons, most years showed a similar
DSD. In winter the mean of 2013 and 2016, in spring the mean of 2017, and in summer the mean of 2014 deviated clearly from the seasonal mean. The seasonal mean $N(D)$ of winter and autumn had the highest drop concentration at the smallest four diameters, while the seasonal mean $N(D)$ in the summer had the highest drop concentration for larger diameters. The fitted gamma distribution provided lower drop concentrations compared to the seasonal mean for diameters up to around $1 \mathrm{~mm}$ (except at the first diameter of $0.1875 \mathrm{~mm}$ ) and similar or higher drop concentrations for larger diameters. The difference between gamma distribution and seasonal mean was notable for diameters larger than $5.25 \mathrm{~mm}$, which might be caused by the low occurrence of drops with this diameter.

In Fig. 2 the seasonal median of the measured fall velocity is compared with the seasonal median values of each year and the terminal fall velocity based on the equation from Atlas et al. (1973). The yearly seasonal median values were similar to the seasonal median up to a diameter of $3.25 \mathrm{~mm}$ (winter, spring) and $5.25 \mathrm{~mm}$ (summer, autumn). At diameters larger than that, the 

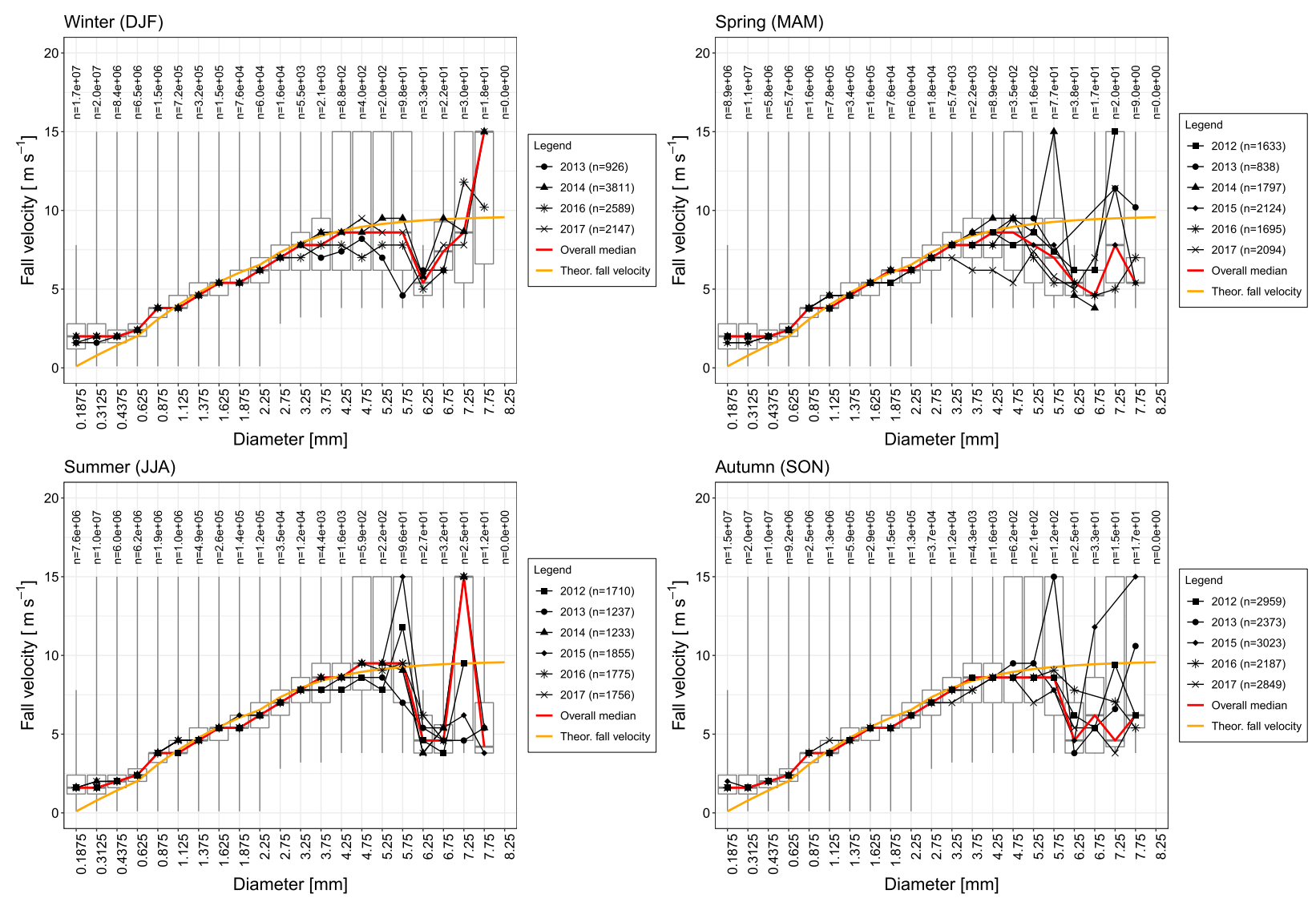

FIG. 2. Median 10-min drop fall velocity per millimeter diameter for different seasons and years. The orange line describes the terminal velocity described by Atlas et al. (1973). The number of analyzed 10-min intervals is given in parentheses next to the years, and the number of analyzed drops for the seasonal median is given for each diameter separately on the top of each boxplot.

yearly median values for some diameters deviated notably from each other and from the seasonal median. Contrarily to $N(D)$, the seasonal median was more or less the same for all seasons except for larger diameters. Comparing the seasonal median fall velocity with the terminal velocity calculated after Atlas et al. (1973), a clear difference was observed for most of the diameters. At diameters up to $1.25 \mathrm{~mm}$ the seasonal median was higher than the terminal velocity. In contrast, the seasonal median was lower compared to the terminal velocity at diameters larger than $1.875 \mathrm{~mm}$. The largest deviation was found for drops with a diameter of $6.25 \mathrm{~mm}$ and larger, where the seasonal median based on the LPM measurements showed even a decrease in the fall velocity. The boxplot of the analyzed measurements indicated a low variation of the fall velocities, especially for drops with a diameter of 6.25 and $6.75 \mathrm{~mm}$. Possible causes for this unexpected result are mentioned in section 4.

The abovementioned variations of $N(D)$ and fall velocity influenced $\operatorname{KE}(D)$. The seasonal 10 -min mean values of the mentioned years in $N(D)$ also show the largest deviation from the seasonal mean of $\operatorname{KE}(D)$ (Fig. 3). The mean seasonal peak values of $\operatorname{KE}(D)$ were clearly higher in the second half-year (summer, autumn) than in the first half-year (winter, spring). The peak of the seasonal mean $\operatorname{KE}(D)$ was highest in summer where $N(D)$ with a diameter larger than $0.625 \mathrm{~mm}$ was highest. The peak of the seasonal mean in winter was the lowest and only half as high as in summer. Furthermore, the diameter related to the peak value of the mean seasonal value was largest in summer, which may be of due to the higher concentration of larger drops in summer compared to the other seasons. In general, $\operatorname{KE}(D)$ was lower for smaller drops because of lower mass and slower fall velocity, while $\operatorname{KE}(D)$ was lower for larger drops because these were few. To estimate the influence of the fall velocity on $\operatorname{KE}(D)$, the seasonal 10-min mean number of drops per diameter was calculated based on the available measurements. This number and the terminal fall velocity calculated after Atlas et al. (1973) where used as input for the line plotted as "Theor. calculation" in Fig. 3. The comparison with the seasonal 10-min mean 

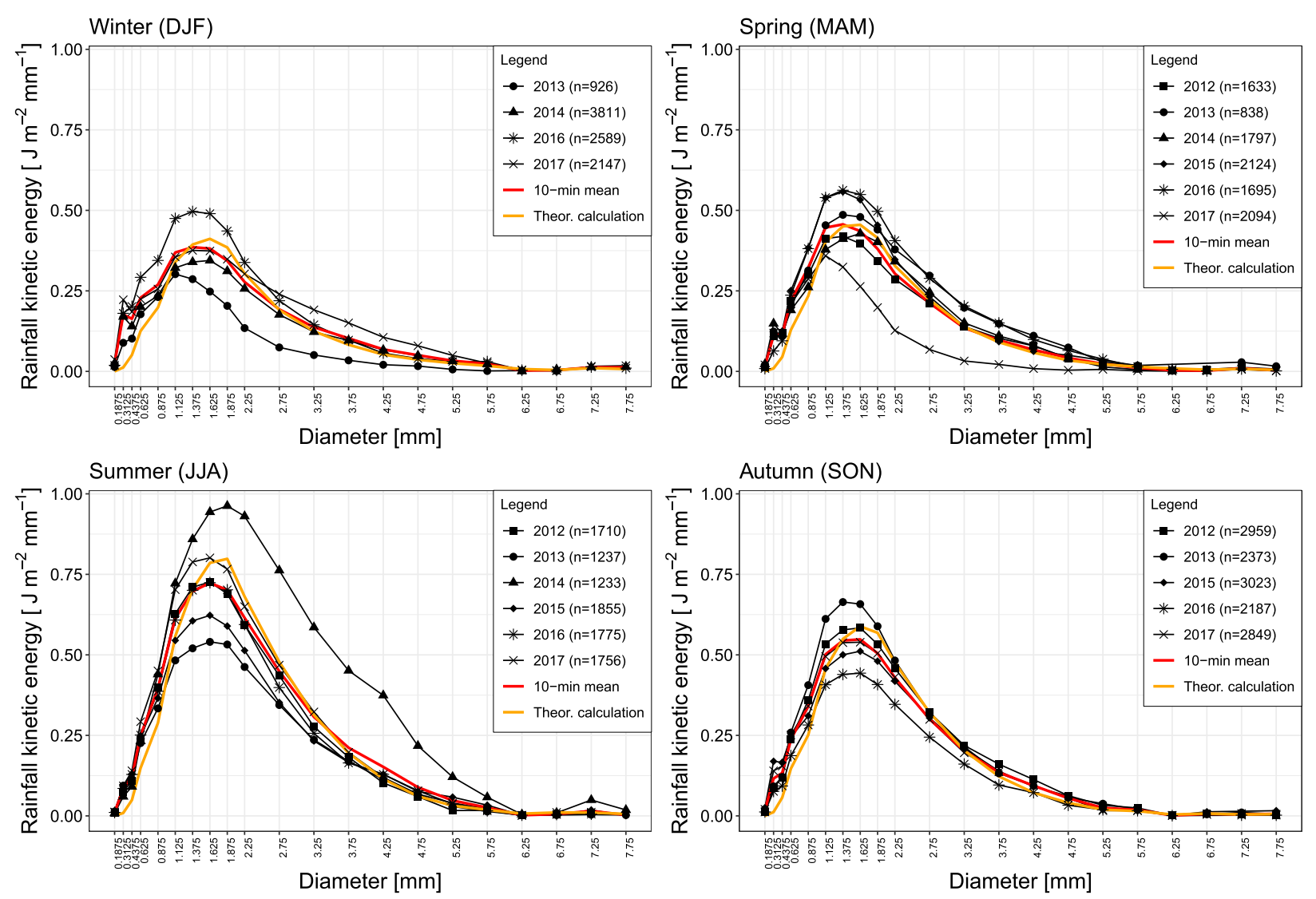

FIG. 3. Mean 10-min rainfall kinetic energy per millimeter diameter $[\operatorname{KE}(D)]$ for different seasons and years. The orange line describes the $\operatorname{KE}(D)$ based on the mean seasonal number of drops and the terminal fall velocity described by Atlas et al. (1973). The number of analyzed 10-min intervals is given in parentheses for each year separately.

value based on the measurements showed that (i) at smaller diameters $\operatorname{KE}(D)$ based on the measurements was higher probably due to the higher median fall velocities and (ii) the value of the peak as well as the diameter with the highest peak were different. Higher terminal fall velocities compared to the median fall velocities at these diameters could cause the last mentioned point.

Laboratory tests show that not only single events but also the cumulative rainfall kinetic energy influence the erosion of the leading edges of the wind turbine blades. Therefore, it is beneficial to know the seasonal cumulative $\operatorname{KE}(D)$. Figure 4 shows clear differences between the single years for some seasons (especially winter). Apart from differences in $N(D)$, these differences can be related to the number of 10 -min intervals with rain. The peaks of the mean seasonal cumulative distributions were highest in autumn and lowest in spring. This result is contrary to the 10 -min mean value but caused by the time where it is actually raining. Independent of the season, drops with a diameter between 0.875 and $2.25 \mathrm{~mm}$ provided between $62 \%$ and $69 \%$ of the cumulative KE but constituted only $2 \%-4 \%$ of the drop concentration.

\section{b. Relationship between wind speed and rainfall kinetic energy as well as other rainfall parameters}

To investigate the relationship between KE, RR, and wind speed, we analyzed the joint probability of $\mathrm{RR}$ and wind speed affecting the KE. In relation to LEE this is of interest, because Bech et al. (2018) propose a reduced tip speed of the wind turbine blades during events with high RR to reduce erosion. Furthermore, the joint probabilities of RR and wind speed affecting the number of 10-min intervals with rain and the rain amount were also calculated to see whether similar probabilities can be expected like for KE. We considered LPM data of the 6-yr observation period with a temporal resolution of $10 \mathrm{~min}$ to determine the cumulative values of 10-min intervals with rain, rain amount and KE. In the next step, we calculated the probability of an increase of 10-min intervals with rain, rain amount and KE depending on the observed values within a specific $\mathrm{RR}$ interval $(<1,1-5,5-10,10-20$, 

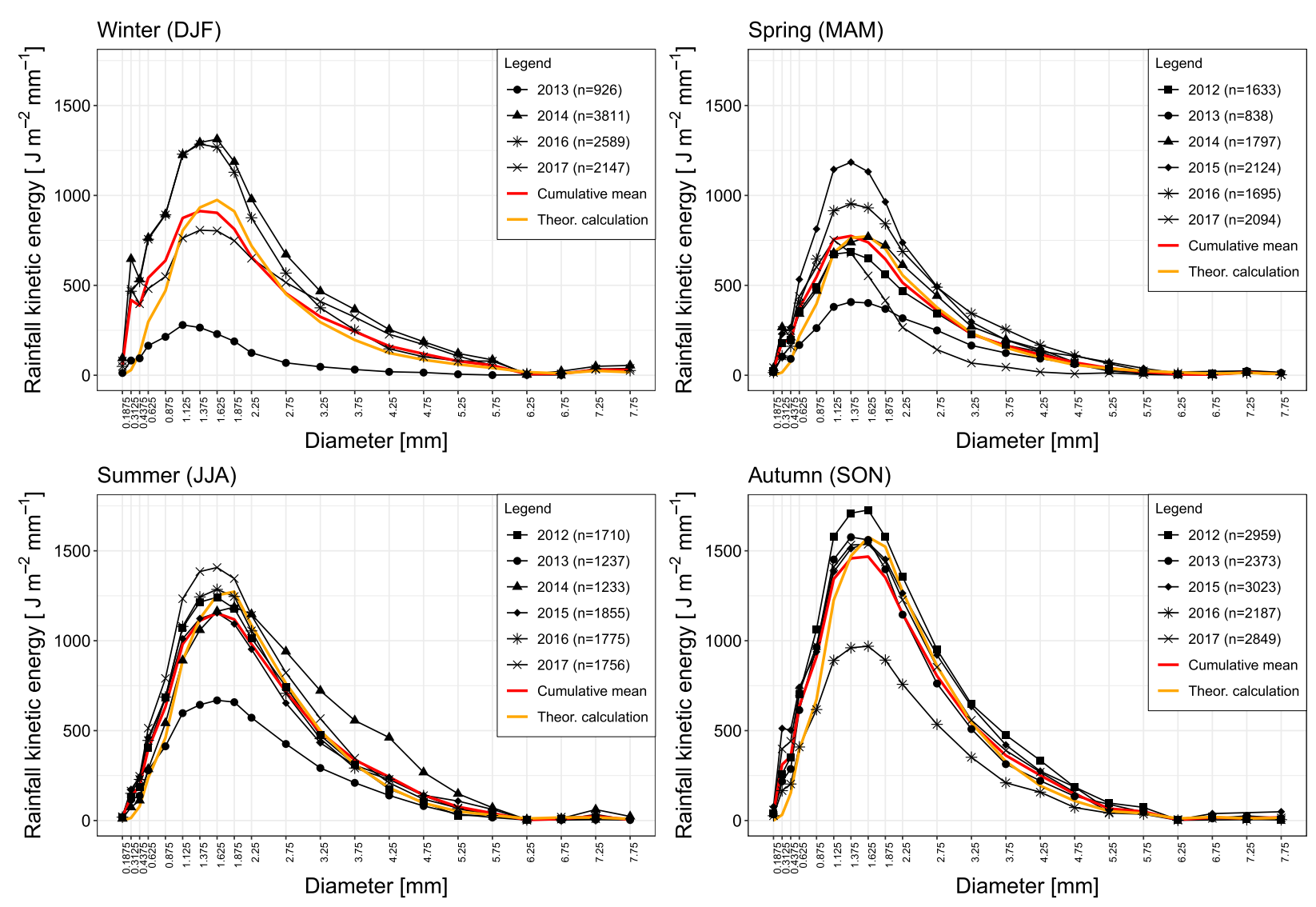

FIG. 4. Cumulative rainfall kinetic energy per millimeter diameter $[\operatorname{KE}(D)]$ for different seasons and years. The orange line describes the $\operatorname{KE}(D)$ based on the mean seasonal number of drops, the mean number of 10-min intervals with rain, and the terminal velocity described by Atlas et al. (1973). The number of analyzed 10-min intervals is given in parentheses for each year separately.

and $\left.>20 \mathrm{~mm} \mathrm{~h}^{-1}\right)$ and wind speed interval $(0-3,3-6,6-9$, 9-13, and above $13 \mathrm{~m} \mathrm{~s}^{-1}$ ).

The highest probabilities occurred in the wind speed interval 3 to $6 \mathrm{~m} \mathrm{~s}^{-1}$ (Fig. 5). The number of 10-min intervals was dominated by $\mathrm{RR}<1 \mathrm{~mm} \mathrm{~h}^{-1}$ but rain amount and KE had their highest probabilities for RR between 1 and $5 \mathrm{~mm} \mathrm{~h}^{-1}$. In fact, for all wind speed intervals, this RR interval caused the highest probabilities of observing an effect on rain amount and KE.

It is interesting to note that the probability of having a 10 -min interval at very low wind speeds $\left(0-3 \mathrm{~m} \mathrm{~s}^{-1}\right)$ and a $\mathrm{RR}>20 \mathrm{~mm} \mathrm{~h}^{-1}$ was 0.00023 . The probability to see an effect on the rain amount and the KE was higher with 0.0046 and 0.0094 . Similar values were observed in the wind speed interval from 3 to $6 \mathrm{~m} \mathrm{~s}^{-1}$. These values are provided in the supplemental material. For wind speeds above $9 \mathrm{~m} \mathrm{~s}^{-1}$ there is no occurrence of RR $>10 \mathrm{~mm} \mathrm{~h}^{-1}$.

The different probabilities to observe a KE increase in connection to wind speed prompted us to think about the wind speed dependence of the parameters defining KE. Therefore, we investigated the correlation between wind speed and the parameters $\mathrm{KE}, D_{m}, N_{W}$, and $V_{m}$ similar to the approach of Testik and Pei (2017). We categorized the 10-min measurements by their LWC, where, for example, values between $>0.15 \mathrm{~g} \mathrm{~m}^{-3}$ and $<0.25 \mathrm{~g} \mathrm{~m}^{-3}$ were assigned to the category $0.2 \mathrm{~g} \mathrm{~m}^{-3}$. The distribution of the parameters was investigated for each LWC value visually and with the Shapiro-Wilk test (Wilks 2006). As in most cases no normal distribution was given, Kendall's $\tau$ and its significance were calculated for all cases (Wilks 2006). By simultaneously analyzing the significance of Kendall's $\tau$ of the LWC subgroups, the so-called multiplicity problem arises. The probability of making at least one type I error (rejection of true hypothesis) increases with an increasing number of individual tests that are based on the same dataset (i.e., LWC in this study). In literature different options are presented to tackle this problem. An easy, and therefore probably popular, method is to reduce the probability of at least one type I error (familywise error rate) by adapting the $p$ value for individual tests with the Bonferroni method (Heiberger and Holland 2015). Taking an overall probability of 0.05 for a type I error, the Bonferroni method leads to a 
(a) 10-minute intervals (cumulative sum: 21729 10-min intervals)

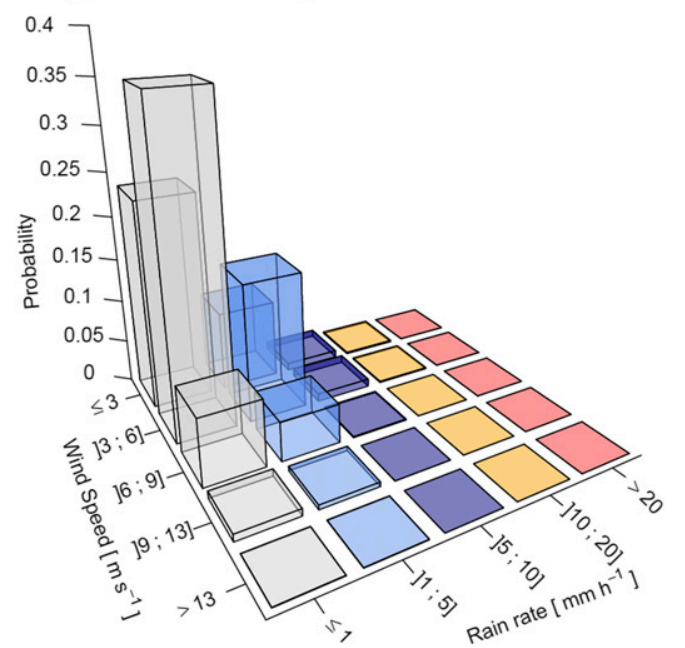

(b) Rain amount (cumulative sum: $3848 \mathrm{~mm}$ )

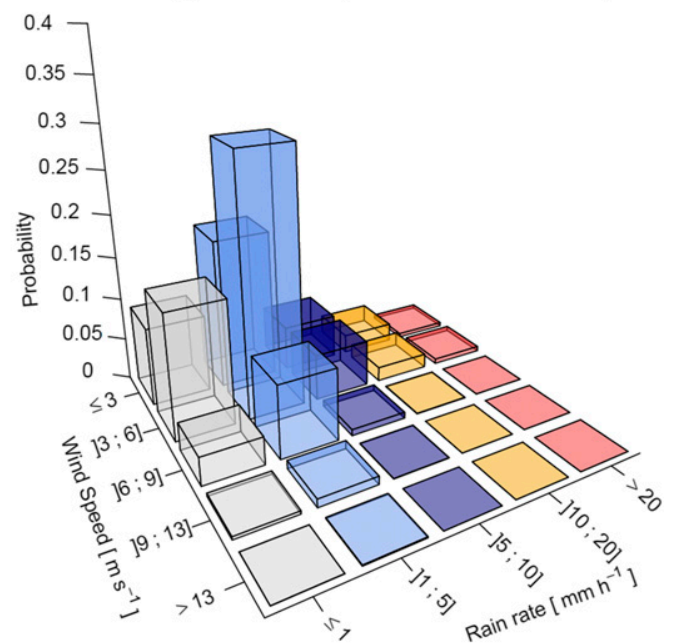

(c) Rainfall kinetic energy (cumulative sum: $47516 \mathrm{~J} \mathrm{~m}^{-2}$ )

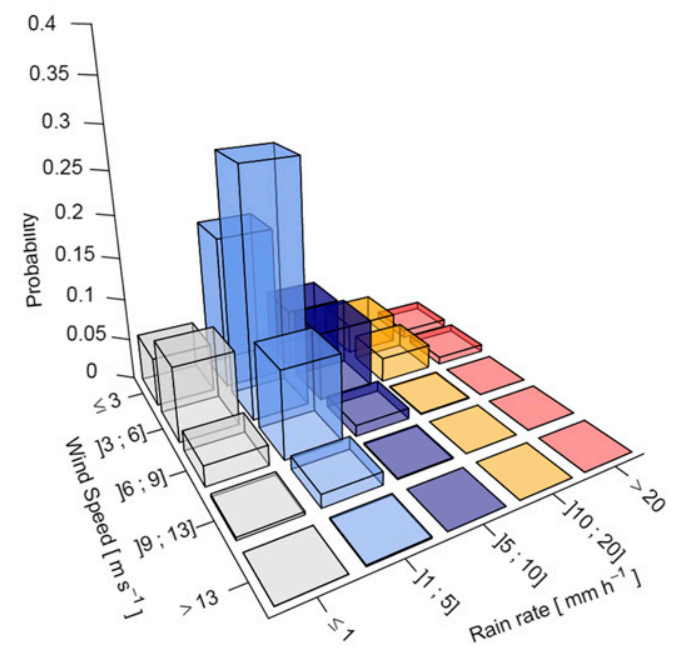

FIG. 5. Joint probability of wind speed and rain rate (RR) affecting (a) the number of 10-min intervals with rain, (b) rain amount, and (c) rainfall kinetic energy (KE) based on 6 years of measurements.

$p$ value of 0.007 for the individual tests of the LWC subgroups in this study.

Table 4 gives an overview of Kendall's $\tau$ values and their significance regarding LWC values between 0.2 and $0.8 \mathrm{~g} \mathrm{~m}^{-3}$ with 0.1 steps. For higher LWC values the number of observations was below 30 , which we saw as a too small data sample to analyze. Kendall's $\tau$ between wind speed and KE was significantly negative for all LWC values given in Table 4. A negative value in this case implies a decrease of $\mathrm{KE}$ with increasing wind speed. As KE was calculated with the vertical fall speed measured by the disdrometer, one can also interpret this $\mathrm{KE}$ value as the vertical component of the overall KE. The Kendall's $\tau$ between wind speed and $D_{m}$ was significantly negative for 4 out of $7 \mathrm{LWC}$ values. A negative slope means that $D_{m}$ decreases with increasing wind speed. In accordance with this result is the significantly increase of $N_{W}$ with increasing wind for 4 out of $7 \mathrm{LWC}$ values. This result indicates that the number of small drops increases with wind speed. Finally, Kendall's $\tau$ between wind speed and $V_{m}$ were significantly positive for 4 out of 7 individual tests. This positive correlation implies an increase of $V_{m}$ with increasing wind speed. The latter result was unexpected as $D_{m}$ decreases and is therefore analyzed more deeply in section 4 . The fraction of significant correlations is nearly the same if applying a $p$ value of 0.05 for the individual tests.

It is noted that Kendall's $\tau$ values were quite low. That means that other parameters apart from wind speed influence KE, $D_{m}, N_{W}$, and $V_{m}$.

Figure 6 shows the above described correlation between wind speed and KE, $D_{m}, N_{W}$, and $V_{m}$ for measurements with a LWC of $0.7 \mathrm{~g} \mathrm{~m}^{-3}$. The measurements 
having a much lower KE, $D_{m}$, and $V_{m}$ and higher $N_{W}$ compared to the majority are notable. They relate to the same event and might be either extreme values or values not captured and removed by the quality control.

\section{c. Relationship between rainfall kinetic energy and rain rate}

Our initial intention was to compare the error of the KER-RR relationship of Wischmeier and Smith (1958) and an adapted equation using the same type but coefficients based on the LPM data from Voulund. The equation from Wischmeier and Smith (1958) reads as follows:

$$
\mathrm{KER}=\mathrm{RR}\left(11.87+8.73 \times \log _{10} \mathrm{RR}\right) .
$$

The adapted equation was trained using the ordinary least squares (OLS) method to minimize the sum of squares of the residuals considering the 6-yr qualitycontrolled 10-min LPM data to calculate KE and RR. A measurement with a RR of $39 \mathrm{~mm} \mathrm{~h}^{-1}$ and KER of $720 \mathrm{~J} \mathrm{~m}^{-2} \mathrm{~h}^{-1}$ was observed in an event in September 2017. Measurements before and afterward had lower values ( $\mathrm{RR}<25 \mathrm{~mm} \mathrm{~h}^{-1}$ and KER $<440 \mathrm{~J} \mathrm{~m}^{-2} \mathrm{~h}^{-1}$ ). We concluded that this measurement is an extreme value, because nothing similar was observed in the 6 years. Therefore, this value was disregarded (also in further steps), because we were focusing on general relationships and less on extreme values. The result was following regression equation:

$$
\begin{aligned}
& \text { KER }=\operatorname{RR}\left(9.55+9.66 \times \log _{10} \mathrm{RR}\right), \\
& \text { where } \leq 30 \mathrm{~mm} \mathrm{~h}^{-1} .
\end{aligned}
$$

Both RR-KER relationships are visualized in Fig. 7. The comparison of the root-mean-square error (RMSE) and mean absolute error (MAE) using the same data as for the training of the equation shows that Eq. (12) had a lower error (Table 5).

When fitting linear regression lines, it is also important to analyze the following statistical properties: (i) normal distribution of the residuals, (ii) homoscedasticity of the residuals, and (iii) linearity of the model. Equation (12) did not fulfill these assumptions, and neither did the equation from Wischmeier and Smith (1958). By training other regression types based on published relationships mentioned in Petru and Kalibová (2018), it turned out that all of them failed in this residual analysis.

To overcome this issue, regression lines were trained for three RR ranges: $\mathrm{RR} \leq 1 \mathrm{~mm} \mathrm{~h}^{-1}, 1<\mathrm{RR} \leq 5 \mathrm{~mm} \mathrm{~h}^{-1}$, and $5<\mathrm{RR} \leq 30 \mathrm{~mm} \mathrm{~h}^{-1}$. The training process can be described as a forward stepwise selection. To improve the model performance and to fulfill the mentioned residual 

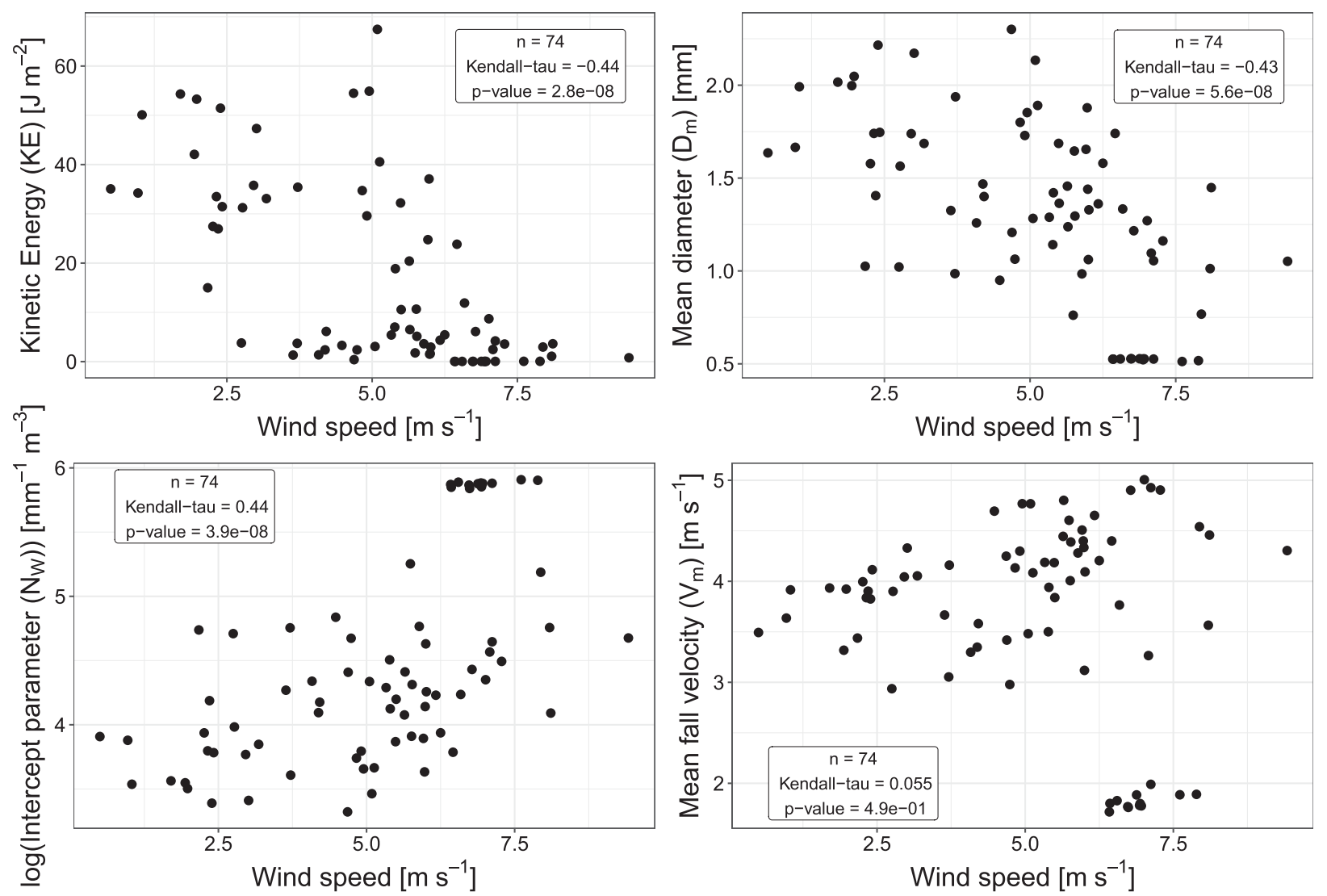

FIG. 6. Scatterplot between wind speed and rainfall kinetic energy (KE), mean diameter $D_{m}$, intercept parameter $N_{W}$, and mean fall velocity $V_{m}$ considering 10-min measurements with a liquid water content (LWC) of $0.7 \mathrm{~g} \mathrm{~m}^{-3}$. Each subplot contains the number of observations $n$, Kendall's $\tau$ values, and its significance.

analysis, the following two points were considered in the training phase: (i) transformation of $\mathrm{KE}$ to get linearity and (ii) adding of polynomials to improve the model. Each trained model was evaluated by its residual analysis as well as by the Akaike information criterion (AIC) and the $p$ value of the $F$ test to consider only significant parameters in the model.

The statistical training resulted in the following equations:

$$
\begin{aligned}
& \mathrm{KER}=10^{\left(-0.68+4.12 \times \mathrm{RR}-4.42 \times \mathrm{RR}^{2}+1.92 \times \mathrm{RR}^{3}\right)}, \\
& \text { where } \quad 0.1<\mathrm{RR} \leq 1 \mathrm{~mm} \mathrm{~h}^{-1},
\end{aligned}
$$

$$
\begin{aligned}
& \mathrm{KER}=10^{\left(0.28+0.77 \times \mathrm{RR}-0.14 \times \mathrm{RR}^{2}+0.01 \times \mathrm{RR}^{3}\right)}, \\
& \text { where } \quad 1<\mathrm{RR} \leq 5 \mathrm{~mm} \mathrm{~h}^{-1}, \\
& \mathrm{KER}=-15.22+19.09 \times \mathrm{RR}+0.17 \times \mathrm{RR}^{2}, \\
& \text { where } \quad 5<\mathrm{RR} \leq 30 \mathrm{~mm} \mathrm{~h}^{-1} .
\end{aligned}
$$

All fitted regression lines are plotted in Fig. 7. The RMSE and MAE values using the same data as for the training of the equation are listed in Table 5. The comparison of the different RMSE values shows that although Eq. (12) fails in the residual analysis, it actually had a similar error compared to Eqs. (13)-(15) for the three specific RR ranges that fulfill all requirements.

\section{Discussion}

The analyzed disdrometer data showed a seasonal variation of the mean 10-min values of $\operatorname{KE}(D)$ and $N(D)$ (Fig. 1,3). While the high cumulative values of $\operatorname{KE}(D)$ in summer are caused by the higher mean 10 -min $N(D)$ values, the high cumulative values in autumn are caused by the higher number of 10 -min intervals with rain (Fig. 4). Our findings related to the cumulative $\operatorname{KE}(D)$ are comparable to the one of Davison et al. (2005), who reports higher KE in summer and autumn in the United Kingdom using statistical relationships between KE and daily rain amount. Leek and Olsen (2006) analyze the erosivity for Denmark using daily precipitation amounts. They find the highest erosivity factors in late summer and early autumn. Obviously, the seasonal 


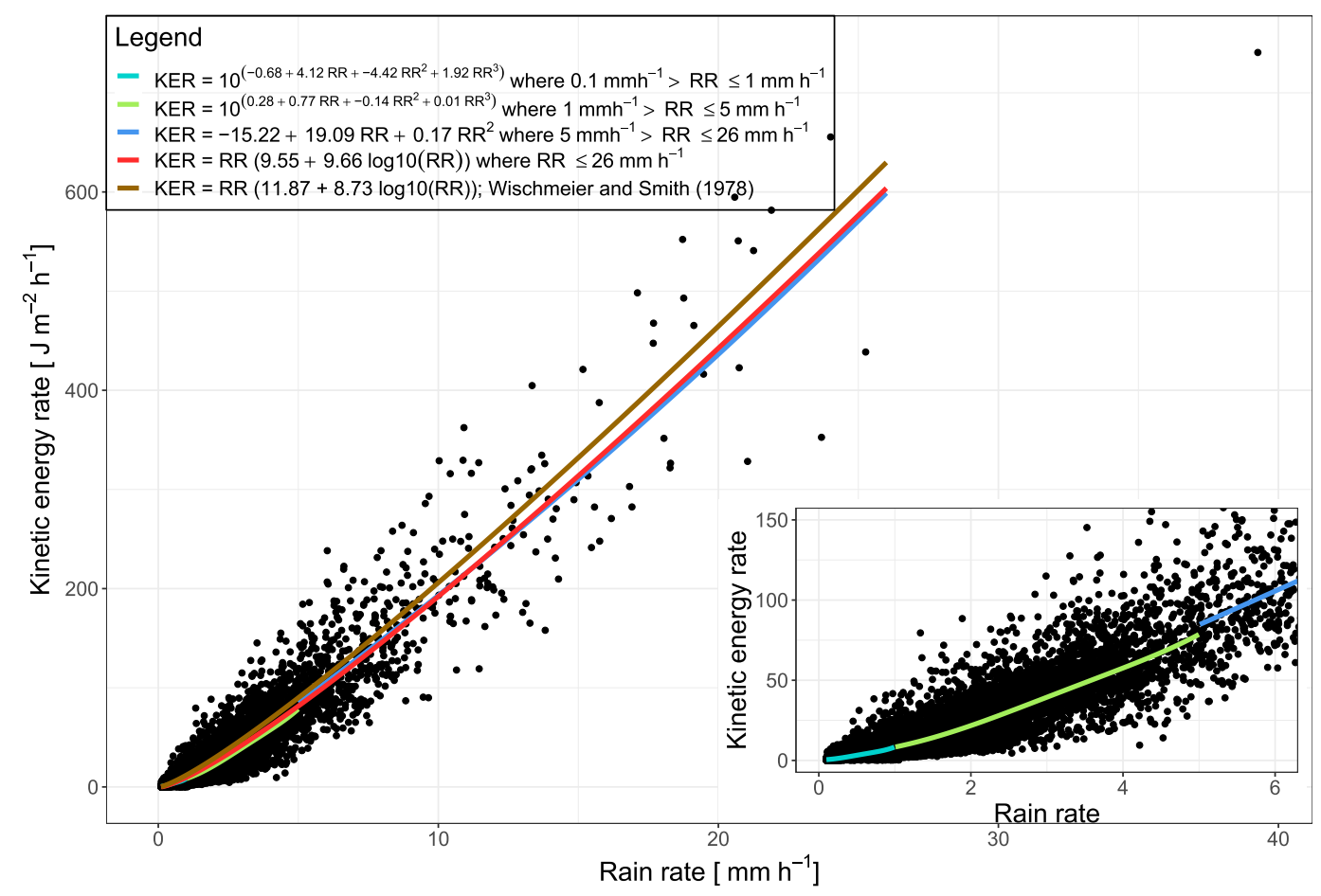

FIG. 7. Scatterplot and linear regression lines between rainfall kinetic energy rate (KER) and rain rate (RR). The included small figure shows a detailed view of the scatterplot and some of the regression lines within $0<\mathrm{RR}<6 \mathrm{~mm} \mathrm{~h}^{-1}$.

variation of $N(D)$ influences $\mathrm{KE}(D)$. In Denmark rain in the summer half-year is often caused by convective events (Mäkelä et al. 2014; Taszarek et al. 2019), while in the winter half-year rain is more related to fronts from systems that are coming or forming over the Atlantic with a high percentage of stratiform rain. As different microphysical processes cause convective and stratiform rain, the underlying $N(D)$ is different and causes the seasonal variation of the mean 10 -min values of $N(D)$ and $\operatorname{KE}(D)$. The causes for annual variation are numerous and may be related also for example to the current sea ice extent or teleconnections (e.g., North Atlantic Oscillation). The strong deviation of the winter values in 2013 from the seasonal mean might also be influenced by the high percentage of snow in that winter (see also Con3 in Table 3). The most unexpected result in this connection is the deviation of the median seasonal fall velocity from the terminal fall velocity of Atlas et al. (1973). It was shown that this deviation influenced the seasonal mean values of $\mathrm{KE}(D)$ observing more $\mathrm{KE}(D)$ at smaller diameters using measured data (Figs. 3, 4). The cause for the reduction of the median fall velocity especially at larger diameters is not completely reasonable, especially as the values are within the $60 \%$ limit of fall velocity set in the quality control. The wind speed during events with larger drops was left skewed distributed. Hence, the lower fall velocity cannot just be explained by high wind speed like in Thurai et al. (2019). Splashing from the housing or a wrong classification by the LPM disdrometer could be other explanations. Although large drops are less often observed, it is still important to know their correct fall velocity to reduce the uncertainty when using them in cumulative KE values. The

TABLE 5. RMSE and MAE considering different relations between rainfall kinetic energy rate (KER) and RR.

\begin{tabular}{lccc}
\hline \hline & & RMSE/MAE $\left(\mathrm{J} \mathrm{m}^{-2} \mathrm{~h}^{-1}\right)$ & \\
\cline { 2 - 4 } & $\begin{array}{c}\text { Rain rate specific equations } \\
\text { [Eqs. (13)-(15)] }\end{array}$ & $\begin{array}{c}\text { General equation } \\
\text { [Eq. (12)] }\end{array}$ & $\begin{array}{c}\text { Wischmeier and Smith (1958) } \\
\text { [Eq. (11)] }\end{array}$ \\
\hline $\mathrm{RR} \leq 1 \mathrm{~mm} \mathrm{~h}^{-1}$ & $2.28 / 1.40$ & $2.26 / 1.45$ & $2.44 / 1.58$ \\
$1>\mathrm{RR} \geq 5 \mathrm{~mm} \mathrm{~h}^{-1}$ & $11.40 / 7.59$ & $11.21 / 7.53$ & $12.16 / 8.73$ \\
$\mathrm{RR}>5 \mathrm{~mm} \mathrm{~h}^{-1}$ & $42.17 / 31.23$ & $42.24 / 31.04$ & $31.23 / 33.26$ \\
\hline
\end{tabular}


effect of nonspherical drops and assuming an equivolumetric diameter on the KE values is not investigated in this study. Fernández-Raga et al. (2010) point out that the volume of drops is overestimated by assuming a sphere instead an ellipsoid as a drop shape.

Investigations showed that rain events with high RR had a low occurrence probability. Such events occurred only at low wind speeds. For comparison, the probability of an increase in rain amount and KE during such conditions was higher (Fig. 5). This picture of decreasing joint probabilities of observing 10-min intervals, rain amount or KE during high RR and high wind speeds is supported by Hasager et al. (2020). They also observe fewer measurements with increasing RR and wind speed. Furthermore, the decrease of KE with increasing wind speed is shown by Kendall's $\tau$ values in Table 4. This result is contrary to the result of Pedersen and Hasholt (1995), Erpul et al. (2003), and Fox (2004) who state an increase of KE with increasing wind speed. One possible explanation for this difference is that they compose the fall velocity into a vertical component (terminal velocity in still air) and horizontal component (wind speed) whereas in this study only the measured vertical component of the fall velocity for calculating KE was considered. Fox (2004) writes that at a certain horizontal wind speed the KE due to the horizontal wind component dominates over the KE due to the vertical fall velocity. This is supported by Pedersen and Hasholt (1995) who show for example that at low RR the KE increases from 8 to $112 \mathrm{~J} \mathrm{~m}^{-2} \mathrm{~mm}^{-1}$ considering a wind speed increase from 0 to $20 \mathrm{~m} \mathrm{~s}^{-1}$. The horizontal component also leads to an impact angle of the drop related to the surface (e.g., Erpul et al. 2003). Furthermore, wind adds not only a horizontal component but also a vertical component as investigated for example by Kim and Song (2018).

Investigating the wind speed dependence of the $\mathrm{KE}$ defining parameters mass and velocity helps to understand our result better. The mass can be described with the parameters $D_{m}$ and $N_{W}$. Parameter $D_{m}$ shows a decrease while $N_{W}$ increases with increasing winds speed. Testik and Pei (2017) report the same result mentioning breakup of drops as a cause. The change of $D_{m}$ and $N_{W}$ would lead to a reduction of KE when keeping the fall velocity constant. In contrast, the parameter $V_{m}$ showed an increase with increasing wind speed. That would lead to an increase of KE when keeping the mass/diameter constant. As a simplification, one could say that as the mass $\left(D_{m}\right.$ and $\left.N_{W}\right)$ goes into the equation of KE with the power of three, the velocity $\left(V_{m}\right)$ only with the power of two, the increase of $V_{m}$ cannot compensate the reduction of KE due to smaller $D_{m}$. However, one would expect a decreasing $V_{m}$ due to decreasing $D_{m}$ values. In general, an increase of the fall velocity of drops with increasing wind speed is correct if considering the resultant fall velocity as vector addition of vertical and horizontal movements (see Fig. 1 in Pedersen and Hasholt 1995). Hence, an increase of the wind speed can compensate the reduction of fall velocity due to a smaller diameter. Furthermore, MonteroMartínez and García-García (2016) observe an increase of the number of drops with superterminal velocity during high wind speeds for drop diameters smaller than $0.7 \mathrm{~mm}$. They mention that one of the reasons might be that the drop was involved in a breakup process shortly before being measured and has still the higher velocity of its parent drop. Nevertheless, measuring fall velocities during high wind conditions is challenging and measurement errors are unavoidable when using a laser disdrometer like LPM. These measurement errors can be observed because the drop is not falling in the center of (Frasson et al. 2011) or with an angle through (Angulo-Martínez et al. 2018) the laser beam.

It is important to note that situations with a high KE do not need necessarily lead to erosion of soil or wind turbine blade material. Factors like impact angle, soil type/wind turbine blade material, liquid layer on the surface, or the shape of the drop also play an important role for the drop impact and therefore in the erosion process (Yarin 2006).

By training regression equations for different $R R$ intervals based on measured LPM data from Voulund to describe a statistical relationship between KER and $\mathrm{RR}$, we were able to (i) fulfill the requirements of the residual analysis for regression lines and (ii) reduce the RMSE compared to the KER-RR relationship from Wischmeier and Smith (1958). Figure 7 and Table 5 show clearly that Wischmeier and Smith (1958) do not describe the relationship between KER and RR properly in the investigated area. This might be different for other regions in the world. From literature it is obvious that the focus is to find a general KER-RR equation for all RR and less on considering statistical assumptions or different equations for different RR intervals. In times of higher computational power the latter reservation should no longer be a constraint. However, the weakness of the statistical relationship between KER and RR is that the same RR can have different underlying DSD. A way to reduce the uncertainty could be to add further variables to the regression equations like $D_{m}$ as suggested by Carollo et al. (2017). Wen et al. (2019) present data from East China and shows that KER-RR relationships based on seasonal data improve the KER estimation as well. Angulo-Martínez and Barros (2015) mention that the disdrometer sensor also has an influence on the KER-RR relationship, as DSD from 
different disdrometers do not agree and can lead to different KER-RR equations for the same location.

\section{Conclusions}

Rainfall kinetic energy (KE) is one of the main sources for erosion, both soil erosion and erosion of the leading edges of turbine blades (LEE). To improve our understanding of conditions with high KE, we analyzed 6 years of quality controlled Thies Laser Precipitation Monitor (LPM) disdrometer data and wind data in Denmark.

The annual and seasonal variations of the drop size distribution (DSD) and the fall velocity are linked to the annual and seasonal variations of rainfall kinetic energy (KE). Furthermore, high cumulative KE in summer are caused by high values of $N(D)$, while the high cumulative KE in autumn are caused by a high number of 10-min intervals with rain. These results show that in Denmark KE varied clearly during the year and therefore also the probability of events with high KE. Independent of the location, the seasonality aspect is of interest for the wind turbine blade inspections, where the status of LEE is usually checked in summer, and in agriculture, where the ground cover on the fields becomes less in autumn in the mid- and high latitudes.

Considering only the 10-min intervals with rain, the probability of observing rain is highest for a rain rate (RR) below $1 \mathrm{~mm} \mathrm{~h}^{-1}$. In contrast, the probability of an increase in rain amount or KE is highest for a RR between 1 and $5 \mathrm{~mm} \mathrm{~h}^{-1}$. We also showed that rain events with $\mathrm{RR}>10 \mathrm{~mm} \mathrm{~h}^{-1}$ occurred only for wind speeds up to $9 \mathrm{~m} \mathrm{~s}^{-1}$. The probability of observing a 10 -min interval with such high $\mathrm{RR}$ was lower compared to the probability of an increase in rain amount or KE. This result is valuable for investigating the consequences of decreased tip speeds during severe rain events on the power production of wind turbines. As decreased tip speeds lead to lower power production, there is an interest to know the magnitude of power production loss.

Correlations indicate that the vertical component of $\mathrm{KE}$ decreases during events with high wind speeds, because of DSD changes. This result is in accordance with literature, where an increase of the horizontal component of KE due to the increased horizontal movement is described. Hence, the impact angle of the drop gets more important when determining the overall KE. This aspect is important to consider for LEE, where wind turbine blades are rotating and the impact angle changes continuously.

In principle, each rain event has the potential to provide high KE. As RR from rain gauges and weather radars are easier available than disdrometer measurements, rainfall kinetic energy rate (KER) is often estimated based on RR. An adapted method is presented to improve the reliability of empirical fits between these two parameters. Investigations showed that wellknown equation types often do not fulfill statistical assumptions like residual distribution.

Summarizing, based on the presented results, the probability of high rainfall kinetic energy is highest in summer and autumn. The wind reduces the vertical component but according to literature increases the horizontal component of KE.

Acknowledgments. We thank the HOBE project and DMI for providing us disdrometer data. This work was supported by Innovation Fund Denmark Grant 615400018B for the project EROSION and the Technical University of Denmark, Department of Wind Energy. We want to thank three anonymous reviewers for their valuable comments.

\section{REFERENCES}

Amirzadeh, B., A. Louhghalam, M. Raessi, and M. Tootkaboni, 2017: A computational framework for the analysis of raininduced erosion in wind turbine blades, part I: Stochastic rain texture model and drop impact simulations. J. Wind Eng. Ind. Aerodyn., 163, 33-43, https://doi.org/10.1016/ j.jweia.2016.12.006.

Angulo-Martínez, M., and A. P. Barros, 2015: Measurement uncertainty in rainfall kinetic energy and intensity relationships for soil erosion studies: An evaluation using PARSIVEL disdrometers in the Southern Appalachian Mountains. Geomorphology, 228, 28-40, https://doi.org/10.1016/j.geomorph.2014.07.036.

_ S. Beguería, and J. Kyselý, 2016: Use of disdrometer data to evaluate the relationship of rainfall kinetic energy and intensity (KE-I). Sci. Total Environ., 568, 83-94, https://doi.org/ 10.1016/j.scitotenv.2016.05.223.

,,-- B. Latorre, and M. Fernández-Raga, 2018: Comparison of precipitation measurements by OTT Parsivel 2 and Thies LPM optical disdrometers. Hydrol. Earth Syst. Sci., 22, 28112837, https://doi.org/10.5194/hess-22-2811-2018.

Atlas, D., R. C. Srivastava, and R. S. Sekhon, 1973: Doppler radar characteristics of precipitation at vertical incidence. Rev. Geophys., 11, 1-35, https://doi.org/10.1029/RG011i001p00001.

Bech, J. I., C. B. Hasager, and C. Bak, 2018: Extending the life of wind turbine blade leading edges by reducing the tip speed during extreme precipitation events. Wind Energ. Sci., 3, 729748, https://doi.org/10.5194/wes-3-729-2018.

Bringi, V. N., V. Chandrasekar, J. Hubbert, E. Gorgucci, W. L. Randeu, and M. Schoenhuber, 2003: Raindrop size distribution in different climatic regimes from disdrometer and dualpolarized radar analysis. J. Atmos. Sci., 60, 354-365, https://doi.org/ 10.1175/1520-0469(2003)060<0354:RSDIDC $>2.0 . C O ; 2$.

Carollo, F. G., V. Ferro, and M. A. Serio, 2017: Reliability of rainfall kinetic power-intensity relationships. Hydrol. Processes, 31, 1293-1300, https://doi.org/10.1002/hyp.11099.

Chen, B., J. Wang, and D. Gong, 2016: Raindrop size distribution in a midlatitude continental squall line measured 
by Thies optical disdrometers over East China. J. Appl. Meteor. Climatol., 55, 621-634, https://doi.org/10.1175/ JAMC-D-15-0127.1.

D'Adderio, L. P., F. Porcù, and A. Tokay, 2018: Evolution of drop size distribution in natural rain. Atmos. Res., 200, 70-76, https://doi.org/10.1016/j.atmosres.2017.10.003.

Das, S., and C. Chatterjee, 2018: Rain characterization based on maritime and continental origin at a tropical location. J. Atmos. Sol.-Terr. Phys., 173, 109-118, https://doi.org/10.1016/ j.jastp.2018.02.011.

Davison, P., M. G. Hutchins, S. G. Anthony, M. Betson, C. Johnson, and E. I. Lord, 2005: The relationship between potentially erosive storm energy and daily rainfall quantity in England and Wales. Sci. Total Environ., 344, 15-25, https://doi.org/10.1016/ j.scitotenv.2005.02.002.

Dolan, B., B. Fuchs, S. A. Rutledge, E. A. Barnes, and E. J. Thompson, 2018: Primary modes of global drop size distributions. J. Atmos. Sci., 75, 1453-1476, https://doi.org/10.1175/ JAS-D-17-0242.1.

Erpul, G., L. D. Norton, and D. Gabriels, 2003: The effect of wind on raindrop impact and rainsplash detachment. Trans. ASAE, 46, 51-62, https://doi.org/10.13031/2013.12548.

Feingold, G., and Z. Levin, 1986: The lognormal fit to raindrop spectra from fontal convective clouds in Israel. J. Climate Appl. Meteor., 25, 1346-1363, https://doi.org/10.1175/15200450(1986)025<1346:TLFTRS > 2.0.CO;2.

Fernández-Raga, M., and Coauthors, 2010: The kinetic energy of rain measured with an optical disdrometer: An application to splash erosion. Atmos. Res., 96, 225-240, https://doi.org/ 10.1016/j.atmosres.2009.07.013.

Fox, N. I., 2004: Technical Note: The representation of rainfall drop-size distribution and kinetic energy. Hydrol. Earth Syst. Sci., 8, 1001-1007, https://doi.org/10.5194/hess-8-1001-2004.

Frasson, R. P. M., L. K. Cunha, and W. F. Krajewski, 2011: Assessment of the Thies optical disdrometer performance. Atmos. Res., 101, 237-255, https://doi.org/10.1016/j.atmosres.2011.02.014.

Friedrich, K., S. Higgins, F. J. Masters, and C. R. Lopez, 2013: Articulating and stationary PARSIVEL disdrometer measurements in conditions with strong winds and heavy rainfall. J. Atmos. Oceanic Technol., 30, 2063-2080, https://doi.org/ 10.1175/JTECH-D-12-00254.1.

Ghada, W., A. Buras, M. Lüpke, C. Schunk, and A. Menzel, 2018: Rain microstructure parameters vary with large-scale weather conditions in Lausanne, Switzerland. Remote Sens., 10, 811, https://doi.org/10.3390/rs10060811.

Hagen, M., and S. E. Yuter, 2003: Relations between radar reflectivity, liquid-water content, and rainfall rate during the MAP SOP. Quart. J. Roy. Meteor. Soc., 129, 477-493, https:// doi.org/10.1256/qj.02.23.

Hasager, C., F. Vejen, J. I. Bech, W. R. Skrzypiński, A.-M. Tilg, and M. Nielsen, 2020: Assessment of the rain and wind climate with focus on wind turbine blade leading edge erosion rate and expected lifetime in Danish Seas. Renewable Energy, 149, 91102, https://doi.org/10.1016/j.renene.2019.12.043.

Heiberger, R. M., and B. Holland, 2015: Statistical Analysis and Data Display. Springer, 756 pp.

Jaffrain, J., and A. Berne, 2011: Experimental quantification of the sampling uncertainty associated with measurements from PARSIVEL disdrometers. J. Hydrometeor., 12, 352-370, https:// doi.org/10.1175/2010JHM1244.1.

Jensen, K. H., and T. H. Illangasekare, 2011: HOBE: A hydrological observatory. Vadose Zone J., 10, 1-7, https://doi.org/ 10.2136/vzj2011.0006.
Jones, B. K., J. R. Saylor, and F. Y. Testik, 2010: Raindrop morphodynamics. Rainfall: State of the Science, Geophys. Monogr., Vol. 191, Amer. Geophys. Union, 7-28.

Kathiravelu, G., T. Lucke, and P. Nichols, 2016: Rain drop measurement techniques: A review. Water, 8, 29, https://doi.org/ 10.3390/w8010029.

Keegan, M. H., D. H. Nash, and M. M. Stack, 2013: On erosion issues associated with the leading edge of wind turbine blades. J. Phys., 46D, 383001, https://doi.org/10.1088/0022-3727/46/38/ 383001.

Kim, D.-K., and C.-K. Song, 2018: Characteristics of vertical velocities estimated from drop size and fall velocity spectra of a Parsivel disdrometer. Atmos. Meas. Tech., 11, 3851-3860, https://doi.org/10.5194/amt-11-3851-2018.

Larsen, M., and M. Schönhuber, 2018: Identification and characterization of an anomaly in two-dimensional video disdrometer data. Atmosphere, 9, 315, https://doi.org/10.3390/ atmos 9080315 .

Leek, R., and P. Olsen, 2006: Modelling climatic erosivity as a factor for soil erosion in Denmark: Changes and temporal trends. Soil Use Manage., 16, 61-65, https://doi.org/10.1111/ j.1475-2743.2000.tb00175.x.

Letson, F., R. J. Barthelmie, and S. C. Pryor, 2020: Radar-derived precipitation climatology for wind turbine blade leading edge erosion. Wind Energy Sci., 5, 331-347, https://doi.org/10.5194/ wes-5-331-2020.

Liu, X. C., T. C. Gao, and L. Liu, 2013: A comparison of rainfall measurements from multiple instruments. Atmos. Meas. Tech., 6, 1585-1595, https://doi.org/10.5194/amt-6-1585-2013.

Macdonald, H., D. Infield, D. H. Nash, and M. M. Stack, 2016: Mapping hail meteorological observations for prediction of erosion in wind turbines. Wind Energy, 19, 777-784, https:// doi.org/10.1002/we.1854.

Mäkelä, A., S.-E. Enno, and J. Haapalainen, 2014: Nordic lightning information system: Thunderstorm climate of northern Europe for the period 2002-2011. Atmos. Res., 139, 46-61, https:// doi.org/10.1016/j.atmosres.2014.01.008.

Mishnaevsky, L., 2019: Repair of wind turbine blades: Review of methods and related computational mechanics problems. Renewable Energy, 140, 828-839, https://doi.org/10.1016/ j.renene.2019.03.113.

Montero-Martínez, G., and F. García-García, 2016: On the behaviour of raindrop fall speed due to wind. Quart. J. Roy. Meteor. Soc., 142, 2013-2020, https://doi.org/ 10.1002/qj. 2794.

—, A. B. Kostinski, R. A. Shaw, and F. García-García, 2009: Do all raindrops fall at terminal speed? Geophys. Res. Lett., $\mathbf{3 6}$, L11818, https://doi.org/10.1029/2008GL037111.

Naipal, V., C. Reick, J. Pongratz, and K. Van Oost, 2015: Improving the global applicability of the RUSLE model Adjustment of the topographical and rainfall erosivity factors. Geosci. Model Dev., 8, 2893-2913, https://doi.org/10.5194/ gmd-8-2893-2015.

Panagos, P., and Coauthors, 2015: Rainfall erosivity in Europe. Sci. Total Environ., 511, 801-814, https://doi.org/10.1016/ j.scitotenv.2015.01.008.

Pedersen, H. S., and B. Hasholt, 1995: Influence of wind speed on rainsplash erosion. Catena, 24, 39-54, https://doi.org/10.1016/ 0341-8162(94)00024-9.

Petan, S., S. Rusjan, A. Vidmar, and M. Mikoš, 2010: The rainfall kinetic energy-intensity relationship for rainfall erosivity estimation in the Mediterranean part of Slovenia. J. Hydrol., 391, 314-321, https://doi.org/10.1016/j.jhydrol.2010.07.031. 
Petrů, J., and J. Kalibová, 2018: Measurement and computation of kinetic energy of simulated rainfall in comparison with natural rainfall. Soil Water Res., 13, 226-233, https://doi.org/10.17221/ 218/2016-SWR

Pickering, B. S., R. R. Neely III, and D. Harrison, 2019: The Disdrometer Verification Network (DiVeN): A UK network of laser precipitation instruments. Atmos. Meas. Tech., 12, 5845-5861, https://doi.org/10.5194/amt-12-5845-2019.

Salles, C., J. Poesen, and D. Sempere-Torres, 2002: Kinetic energy of rain and its functional relationship with intensity. J. Hydrol., 257, 256-270, https://doi.org/10.1016/S0022-1694(01)00555-8.

Sevruk, B., M. Ondrás, and B. Chvíla, 2009: The WMO precipitation measurement intercomparisons. Atmos. Res., 92, 376-380, https://doi.org/10.1016/j.atmosres.2009.01.016.

Suh, S.-H., C.-H. You, and D.-I. Lee, 2016: Climatological characteristics of raindrop size distributions in Busan, Republic of Korea. Hydrol. Earth Syst. Sci., 20, 193-207, https://doi.org/ 10.5194/hess-20-193-2016.

Taszarek, M., and Coauthors, 2019: A climatology of thunderstorms across Europe from a synthesis of multiple data sources. J. Climate, 32, 1813-1837, https://doi.org/10.1175/ JCLI-D-18-0372.1.

Testik, F. Y., and B. Pei, 2017: Wind effects on the shape of raindrop size distribution. J. Hydrometeor., 18, 1285-1303, https:// doi.org/10.1175/JHM-D-16-0211.1.

Testud, J., S. Oury, R. A. Black, P. Amayenc, and X. Dou, 2001: The concept of "Normalized" distribution to describe raindrop spectra: A tool for cloud physics and cloud remote sensing. J. Appl. Meteor., 40, 1118-1140, https://doi.org/10.1175/ 1520-0450(2001)040<1118:TCONDT>2.0.CO;2.

Thurai, M., M. Schönhuber, G. Lammer, and V. Bringi, 2019: Raindrop shapes and fall velocities in "turbulent times." $A d v$. Sci. Res., 16, 95-101, https://doi.org/10.5194/asr-16-95-2019.

Tokay, A., and P. G. Bashor, 2010: An experimental study of small-scale variability of raindrop size distribution. J. Appl.
Meteor. Climatol., 49, 2348-2365, https://doi.org/10.1175/ 2010JAMC2269.1.

Ulbrich, C. W., 1983: Natural variations in the analytical form of the raindrop size distribution. J. Climate Appl. Meteor., 22, 1764-1775, https://doi.org/10.1175/1520-0450(1983)022<1764: NVITAF $>2.0 . \mathrm{CO} ; 2$.

— , and D. Atlas, 1998: Rainfall microphysics and radar properties: Analysis methods for drop size spectra. J. Appl. Meteor., 37, 912-923, https://doi.org/10.1175/1520-0450(1998) $037<0912$ :RMARPA $>2.0$.CO;2.

Upton, G., and D. Brawn, 2008: An investigation of factors affecting the accuracy of Thies disdrometers. Proc. World Meteorological Organization Tech. Conf. on Instruments and Methods of Observation, St. Petersburg, Russia, WMO, 27-29, https://www.wmo.int/pages/prog/www/IMOP/publications/ IOM-96_TECO-2008/2(10)_Upton_United_Kingdom.pdf.

van Dijk, A. I. J. M., L. A. Bruijnzeel, and C. J. Rosewell, 2002: Rainfall intensity-kinetic energy relationships: A critical literature appraisal. J. Hydrol., 261, 1-23, https://doi.org/10.1016/ S0022-1694(02)00020-3.

Veihe, A., B. Hasholt, and I. G. Schiøtz, 2003: Soil erosion in Denmark: Processes and politics. Environ. Sci. Policy, 6, 3750, https://doi.org/10.1016/S1462-9011(02)00123-5.

Wen, L., K. Zhao, M. Wang, and G. Zhang, 2019: Seasonal variations of observed raindrop size distribution in East China. Adv. Atmos. Sci., 36, 346-362, https://doi.org/10.1007/s00376018-8107-5.

Wilks, D. S., 2006: Statistical Methods in the Atmospheric Sciences. Elsevier, 627 pp.

Wischmeier, W. H., and D. D. Smith, 1958: Rainfall energy and its relationship to soil loss. Trans. $A G U, \mathbf{3 9}, 285$, https://doi.org/ 10.1029/TR039i002p00285.

Yarin, A. L., 2006: Drop impact dynamics: Splashing, spreading, receding, bouncing. ... Annu. Rev. Fluid Mech., 38, 159-192, https://doi.org/10.1146/annurev.fluid.38.050304.092144. 